\title{
El combate contra la serpiente: el triunfo de la tierra velado bajo la aparente muerte del ofidio*
}

\author{
Diana Rodriguez Pérez
}

Universidad de León

RESUMEN. Tanto la mitología griega como la del Oriente Próximo registran una serie de combates que muestran cómo determinados dioses se enfrentan a fuerzas primitivas de la naturaleza, representadas bajo la forma de una serpiente, cuya aniquilación les otorgaría la soberanía sobre el mundo y la instauración de un orden nuevo. No obstante, un detenido análisis de esos relatos revela cómo el poder de la Tierra encarnado en la serpiente no fue nunca aniquilado por completo, sino que pervive de forma latente en el nuevo orden surgido después de la contienda.

Palabras clave: Serpiente, mitología, combates, Pitón, Tifón, Gea, iconografía, Apofis, Tiamat, Arte griego.

ABSTRACT. Both the Greek and the Near East mythology tell us about how the chthonic powers of the Earth, incarnated in the form of a snake, were defeated by the new uranic gods. However, a meticulous analysis reveals that they didn't get rid of the Earth and that its presence is still alive in the new order of the world that arises after the battle.

Key words: Snake, mythology, battles, Python, Typhon, Gaia, iconography, Apep, Tiamat, Greek art.

Son muchos los mitos de pueblos y culturas diferentes que nos transmiten algún episodio cuyo tema es la muerte de una extraordinaria serpiente a manos de un poderoso dios. En esos relatos la serpiente aparentemente muere, tras lo cual el dios vencedor consigue un estatus superior al que gozaba antes de haberse enfrentado con el ofidio. La idea subyacente en esos combates es que la tierra, encarnada por la sierpe, ha sido aniquilada o, al menos, subyugada por completo, pero un análisis más atento de algunos de estos mitos revela un final muy distinto al que se suele creer: la serpiente no muere realmente, sino que sigue presente de una u otra manera en la nueva situación que surge tras su aparente exterminio.

Para ejemplificar semejante hipótesis analizaremos aquí dos relatos bien conocidos de

* Este artículo se enmarca en las labores investigadoras llevadas a cabo gracias a una Beca de Formación del Profesorado Universitario concedida por el Ministerio de Educación y Ciencia. (AP-2004-6605). la mitología griega: la Tifonomaquia y la muerte de la serpiente Pitón de Delfos.

\section{LA TIFONOMAQUIA}

Por el nombre de Tifonomaquia se conoce el combate librado entre Zeus y Tifón, en el que estaba en juego la instauración de un nuevo orden, alentado por el Cronida, frente a uno de los últimos ataques de las fuerzas primitivas, caóticas y, al mismo tiempo, indispensables de la naturaleza, representadas en la figura serpentiforme de Tifón. El esquema de esta contienda se atiene a los patrones que enmarcan otros combates cósmicos entre la serpiente primordial y una divinidad: a raíz de los enfrentamientos surgidos en el seno de una familia divina desencadenados para hacerse con el poder supremo, y cuando uno de sus miembros parece haberse hecho con el trono, hace su aparición un monstruo ofídico que, casi siempre alentado por las fuerzas primitivas subyugadas por el nuevo soberano, desafía la supremacía de éste recién conquistada. Tal suele ser el arquetipo. 
Sobre el combate entre Zeus y Tifón hay varias tradiciones, destacando sobre todo la versión de Hesíodo en la Teogonía y la de Apolodoro en su Biblioteca mitológica, sin olvidar la curiosa variante que ofrece Nonno de Panópolis en las Dionisiacas.

En Apolodoro ${ }^{1}$ el combate se inicia cuando Tifón comienza a lanzar piedras candentes contra el cielo, lo que provoca que los dioses, asustados, huyan a Egipto metamorfoseados en diversos animales. El momento supremo del relato está representado por el duelo que (en el monte Casio, en Siria ${ }^{2}$ ) enfrenta a los dos contendientes: el monstruo logra herir a Zeus con una hoz de acero $^{3}$, lo aprisiona entre sus anillos serpentiformes, le corta los tendones de pies y manos, y los deposita en la cueva Coricia encomendando su vigilancia a la dragona Delfine. No es sino con la ayuda del engaño a Tifón por parte de dioses secundarios, Hermes y Egipán (en Apolodoro) y Cadmo (en Nonno) como Zeus puede sobreponerse, recobrar sus energías, salir victorioso en la contienda ${ }^{4}$ y proclamarse el nuevo dios soberano de los cielos y vencedor

${ }^{1}$ La principal divergencia que se aprecia entre la narración de Hesíodo (seguida por Esquilo y Píndaro) y la de Apolodoro (por Nonno) es el crítico instante en el que Zeus parece ser vencido por Tifón. Mientras en Hesíodo no se alude en ningún momento a este suceso, en Apolodoro el episodio se cuenta abiertamente. Sin duda, esto se debe a que la Teogonía canta un himno a Zeus en el que no hubiera quedado bien visto el episodio que mostrara a un Zeus derrotado. HESIODO, Teogonía 820-880; APOLODORO, Biblioteca I, 6, 3; Esquilo, Prometeo encadenado 350; PÍNDARO, Primera pitica 15, NONNO DE PANÓPOLIS, Dionisiacas.

${ }^{2}$ En el mundo hurrita, el monte al que Tesub, Tamisu e Istar subieron para observar los destrozos causados por Ullikumi, el monstruo de diorita hijo de Kumarbi, es el mismo que el escenario de la contienda de Zeus y Tifón: el monte Hazzi o Casio.

${ }^{3}$ Esa misma hoz fue la usada por Crono para cortar los testículos de su padre y así acabar con su potencia fertilizadora. Según algunas fuentes, también es el arma que usará posteriormente Jasón para matar a la serpiente guardiana del Vellocino de Oro.

${ }^{4}$ Este aspecto, al igual que otros muchos del combate entre Zeus y Tifón, en los que no podemos ahora detenernos, tiene su paralelo en el mundo oriental, con toda una tradición de mitos en los que el dios de la tormenta no podría haberse impuesto sobre el monstruo sino hubiera sido por el auxilio de otros dioses o, en ocasiones, mortales (por ejemplo: Upasiya en el mito hitita, Istar ayudando a Tesub, Ea a Marduk y Seth a Ra). El engaño al monstruo tiene éxito porque éste es un ser bobo, carente de inteligencia, además de glotón, rasgo común de los dragones en los relatos folklóricos. Cf. M. Eliade, Historia de las creencias y de las ideas religiosas. De la prehistoria a los misterios de Eleusis, Madrid, 1978, vol. I, p. 162. del caos caracterizado por las potencias ctónicas representadas en la figura serpentiforme de Tifón.

Las serpientes que conformaban su físico, según podemos ver en las representaciones que del monstruo hicieron helenos, etruscos y romanos, revelan esa identidad ${ }^{5}$ (Lám. 1 y 2): Tifón era hijo de Gea, de la Tierra, aspecto en el que todas las fuentes concuerdan, exceptuando la rara confusión de Higino cuando afirma que Tártaro engendró de Tártara a Tifón ${ }^{6}$. Hesíodo lo hace hijo de Gea y Tártaro, considerando su nacimiento como una venganza por la expulsión de los Titanes del cielo por Zeus. El Himno homérico a Apolo nos lo presenta como hijo de Hera sin la intervención de Zeus, pues ésta se negaba a yacer con su olímpico esposo encolerizada como estaba por el nacimiento partenogenético de Atenea de la cabeza del Cronida. No obstante, Hera no consigue este monstruoso hijo sin antes imprecar a la Tierra, al Cielo y a los Titanes que moraban en el Tártaro. Una tercera versión nos la da un escoliasta, para quien Tifón fue hijo de Gea con la intervención de Crono, idea que parece compartir Ovidio, para quien Tifón era un monstruo salido de lo más profundo de la tierra e hijo de la tierra, aunque el poeta sulmonés no nombra ningún principio masculino. Como vemos, el hecho importante no radica en quién fuera el padre del monstruo, sino en que su madre era la misma Tierra. Este papel de la Tierra al lado de su hijo monstruoso debe de ser particularmente recalcado, pues el sometimiento de Tifón viene a ser, en última instancia, el sometimiento de la propia Gea, aquella diosa madre serpiente que, desde el Paleolítico y como reflejo de la estructura social matrilineal existente, daba la vida, la muerte y la regeneración ${ }^{7}$. Una vez que Tifón es derrotado, el mensaje que se lanza es claro: las armas del gigante son colgadas por Temis de lo alto del vestíbulo del Olimpo a fin de exponerlas como objeto de terror ante la insensata Tierra, madre de futuros gigantes ${ }^{8}$.

${ }^{5}$ F. VIAN, Répertoire des gigantomachies figurées dans l'art grec et romain, Paris, 1951.

${ }^{6}$ Higino, Fábulas 152.

${ }^{7}$ M. GimbUTAS, "La religiosidad de la Diosa en la Europa mediterránea", Tratado de antropología de lo sagrado [3]. Las civilizaciones del Mediterráneo y lo sagrado, Madrid, 1997, pp. 41-63.

${ }^{8}$ NonNO DE PANÓPOLIS, Dionisiacas 710. 
Como decimos, la sublevación de Tifón significa uno de los últimos intentos de la Tierra por resistir al avance de la nueva generación de dioses jóvenes caracterizados por un dinamismo que se contrapone frontalmente al inmovilismo típico de los dioses ancianos que dieron origen al mundo. Es la furia de la Tierra la que da origen a Tifón, y la derrota de su hijo es la suya propia. En casi todos los relatos se ve el sufrimiento físico de ésta a medida que el monstruo va siendo derrotado. Además, los golpes que Zeus descarga no sólo se dirigen a Tifón, sino que al mismo tiempo azota la tierra alrededor de él ${ }^{9}$. Ésta arde, gime ${ }^{10}$, se abre en grietas debido al fuego que origina el rayo, llora al ver el rostro quemado de su hijo -como lo hará en otras ocasiones, cuando vea derrotados también a otros monstruosos vástagos suyos-, se rasga las vestiduras, hace jirones su túnica de piedra, y su cabello formado por árboles es cortado por el viento ${ }^{11}$. La compasión de la Tierra por sus hijos derrotados también se deja ver en un pasaje de las Argonáuticas de Valerio Flaco:

...en torno a ella se ven monstruos enormes de gigantes terrestres en otro tiempo enfrentados por obtener el cielo. Compadecida de éstos, su madre los vistió de rocas, árboles y riscos y los puso en pie a manera de montes que se elevan al cielo ${ }^{12}$.

Hasta el final del combate Gea permanece al lado de su hijo, cuando éste es sepultado bajo el Etna ${ }^{13}$, convirtiéndose así en prisionero dentro de la misma divinidad que lo engendró y de quien adquirió su característica más espanto-

-

${ }^{9}$ Homero, Ilíada II, 780.

${ }^{10}$ Hesiodo, Teogonía 858.

${ }^{11}$ NONNO DE PANÓPOLIS, II, 636.

12 VALERIO FLACO, II, 14.

${ }^{13}$ Sobre la última morada de Tifón son varias las tradiciones. La tradición que lo sitúa bajo el Etna, en Sicilia, arranca de Píndaro, al que siguen Esquilo, Higino, Apolodoro, Nicandro, Ovidio, Filóstrato el Viejo y Valerio Flaco. Cf. A. SILVÁn RodRÍGUEZ, "El mito de Tifón y su recepción en Píndaro", Cuadernos de Filología Clásica: Estudios griegos e indoeuropeos, 12, 2002, pp. 145-161. PínDARO, Primera pítica. Las aguas del lago Serbónide, en Egipto fueron consideradas por Heródoto, Apolonio de Rodas y Plutarco moradas de este monstruo aunque esta localización se debe a la confusión que entre Tifón y Seth, el adversario de Horus, empieza a crecer a partir del siglo VI a.C con los relatos que narraban que Seth fue vencido en este lago. APOLONIO DE RODAS, Argonáuticas II, 1210; HERÓDOTO, Historias III, 5; PlutARCO, Vida de Antonio III, 3. Una tercera localización es la Cueva Coricia, en Cilicia. sa: las serpientes que conformaban su cuerpo. No obstante, la tierra se sobrepone a la adversidad y, quizá por su propio bien, la vemos en Hesíodo instando a Zeus, después de la victoria, a que reine sobre los inmortales ${ }^{14}$.

Esta vez la serpiente ha sido vencida y el dios de la Tormenta puede respirar tranquilo; pero no creemos que los indicios muestren que la Tierra, tampoco esta vez, haya sido totalmente derrotada ni que su hijo haya sido exterminado: si recurrimos al comparativismo con arquetipos similares que nos ofrece el mundo oriental, podremos constatar que, bajo la derrota aparente de la Tierra, ésta ha resultado en realidad vencedora.

La existencia de Tifón no acaba una vez que es vencido, pues en la Teogonía de Hesíodo se relata cómo, a partir de su cuerpo inane, se crean elementos nuevos. Del cuerpo de Tifón emana una nueva creación que da lugar a los vientos soplantes, algunos benéficos y otros maléficos, sobre todo para los marineros. De este modo, aunque el monstruo serpentiforme perdió la batalla contra el cielo, siguió estando presente en el nuevo orden del mundo que en Hesíodo surge tras la contienda, lo que viene a poner de manifiesto que, como representante del caos, Tifón era indestructible. Un monstruo telúrico no puede ser destruido totalmente. Aun en las versiones que no hablan de esta creación a partir de su cuerpo, éste sigue presente: bajo el Etna, en el Tártaro e incluso en las armas colgadas en el vestíbulo del Olimpo, su amenaza, aunque menguada, permanece en estado latente como aviso a generaciones futuras y sobre todo como aviso a la insensata Tierra, madre de futuros gigantes ${ }^{15}$.

No obstante, donde encontramos una manifestación mucho más arcaica de este mitologema es en el mundo babilónico:

\section{EL PARALELO BABILONIO: ENUMA ELISH}

El Poema de la Creación babilónico (Enuma Elish, "cuando en lo alto", son las primeras palabras del himno ${ }^{16}$ nos hace asistir a uno de los más feroces y primitivos combates entre monstruos ofídicos y dioses que sin duda

-

${ }^{14}$ Hesíodo, Teogonía 882

${ }^{15}$ NONNO DE PANÓPOLIS, Dionisiacas 710.

${ }^{16}$ A. Bernabé PajARES, Textos literarios hetitas, Madrid, 1987. 
cautivaron la imaginación de los hombres de la Edad de Hierro, y vino tal vez a representar el paradigma de lo que se consideraba un conflicto cosmogónico entre la diosa madre (la Erde Mutter), protagonista omnímoda de la ancestral mitología y los nuevos dioses varoniles, propios de los invasores que ubicaban la residencia de sus entidades divinas y las hacían dueñas del rayo aterrador. Marduk fue el primer dios que derrotó a la diosa madre y tomó su puesto como dador de vida. Las tablillas que contienen el poema que narra sus hazañas fueron descubiertas en 1848 d.C. en la biblioteca de Asurbanipal, último rey de Asiria, y están datadas hacia 1750 a.C., cuando la dinastía de Hammurabi llegó al poder en Babilonia. Este poema, sin embargo, recoge tradiciones muy anteriores, representando en realidad una síntesis literaria de leyendas y tradiciones arcaicas transmitidas de boca en boca y que acabaron por ser grabadas en piedra y conservadas en santuarios y en palacios sumerios y semitas ${ }^{17}$.

La finalidad de este poema es cantar la gloria de Marduk, dios supremo para los babilonios (y dios de la tormenta), en su combate contra la diosa madre, Tiamat, señora de las aguas saladas y superficiales y representada con forma de serpiente ${ }^{18}$.

Según el relato, al principio sólo existían las aguas primordiales aisladas en dos principios: Apsû, personificación de las aguas dulces, el océano primordial, y Tiamat, que encarnaba las aguas saladas, el mar tumultuoso. De la unión de ambas aguas nacieron Mummu (el futuro mensajero divino) y dos serpientes divinas: Lakhmu y Lakhamu. Más tarde Lakhmu y Lakhamu procrearán a Ansar (el horizonte celeste) y a Kisar (el horizonte terrestre), quienes, a su vez, serán progenitores de una saga divina de la que forman parte dioses poderosos como

\footnotetext{
${ }^{17}$ A. Bernabé, C. García Gual, C. Lemosín y E. PIRART, Mitología y religión del Oriente Antiguo III. Indoeuropeos, Madrid, 1998.

${ }^{18}$ Posiblemente el nombre de Tiamat fue una designación tardía o alternativa de la diosa madre sumeria, la diosa madre Nammu, quien también era la imagen de las aguas primordiales, fuente de la que emergió toda la vida y probablemente representada en forma de serpiente, ya que, en Ur, ha aparecido una diosa con cabeza de serpiente que lleva a su hijo en brazos, datada entre el año 4000-3000 a.C. Baring y Cashford comparan a esta diosa madre sumeria con la imagen hindú de Ananta, la gran serpiente del abismo cósmico sobre la que reposaba el dios Visnú. A. BARING y J. CASHFORD, El mito de la Diosa, Madrid, 2005, p. 221.
}

Anu, Ea (o Nudimmud), Igigi, Anunnaki y muchos más que se reparten los diferentes dominios del universo. El bullicioso alboroto y el constante ruido que los jóvenes dioses provocaban con su incesante ajetreo molestó sobremanera a Apsû, siempre soñoliento, pues la algarabía procreadora no le permitía descansar ${ }^{19}$. Por ello, Apsû de acuerdo con la también irritada Tiamat y por consejo de Mummu, decide aniquilar a sus retoños, pero éstos se enteran y Ea, con sus poderes mágicos, encanta las aguas, apoderándose así de Apsû y Mummu. Después de dar muerte a Apsû, lo transforma en su propia morada sagrada en donde fija su residenciasantuario, donde engendra a Marduk, un ser perfecto revestido con la aureola de diez dioses. Por su parte, Tiamat, deseosa de venganza, engendra una cohorte de monstruos-serpientes llenos de veneno y dotados de poderes divinos. Entre ellos destaca a Kingu, en cuyo pecho fija las Tablillas del Destino, proclamándose jefe $\mathrm{e}^{20}$. Después de una serie de avatares en los que se muestra a distintos dioses huyendo aterrados del campo de batalla frente a Tiamat (también otro rasgo común a varios mitos cosmogónicos, por ejemplo: Indra/Vritra), el feroz Marduk, sobre el carro-tormenta, es enviado por la asamblea divina contra la diosa madre, no sin antes recibir la promesa de ser aceptado como dios supremo si regresara victorioso de la batalla. Con los atributos del dios de la tormenta, los encantamientos mágicos heredados de Ea y los siete vientos malos reta a la serpiente a combate singular (Lám. 3). Acepta ésta, y Marduk, tras pronunciar un conjuro poderoso, desata contra ella los vientos. La diosa fue incapaz de cerrar sus labios y así, lleno su vientre por los vientos, Marduk consigue clavarle una flecha que corta sus entrañas y su corazón. El séquito emprende

-

${ }^{19}$ El marco temporal de estos combates es muy preciso y consta de tres etapas: el primer estado representa la eternidad, el momento en que las cosas son, pero nada se transforma. No hay cambio, movimiento ni diferenciación. En el segundo estado todo cambia tan rápidamente que no hay un punto de referencia para medir el tiempo. Por último, el orden, la tercera etapa, el caos ha sido controlado y existe el tiempo, la cohesión y la expansión, lo cual permite la vida y el reinado de los dioses vencedores. Cf. M. WAKEMAN, God's Battle with the Monster, 1973, p. 42.

${ }^{20}$ Este hecho significa otorgar a Kingu una dignidad que no le corresponde, la dignidad de Anu. Lo mismo ocurre en el mito sumerio de Anzû, cuando esta colosal águila roba las Tablillas del Destino del dios Enlil. Este rasgo, el robo al dios de la Tormenta de los signos de su poder, es común en todos estos mitos cosmogónicos y también está presente en el mito de Tifón, pues éste roba a Zeus sus armas características, el rayo, el trueno y el relámpago. 
la desbandada, pero Marduk los apresa a todos envolviéndolos en una red y arrojándolos a los abismos infernales. Luego se apodera del cadáver de Tiamat, lo despedaza y con semejantes despojos inicia el proceso de creación del cosmos: le aplasta el cráneo con su maza, le pisa las piernas o ata su cola ${ }^{21}$, separa los conductos de su sangre y divide su carne como si fuera un pescado; con una mitad formó el cielo y cerró las dos partes poniendo un guardián para evitar que salieran las aguas. A partir de aquí, se crea un nuevo mundo para los grandes dioses, y aparece el tiempo. Con otro despojo de Tiamat, la saliva, forma las nubes y las llena de agua; de la cabeza forma montes, de sus ojos hace fluir el Éufrates y el Tigris y con su pecho da forma a las montañas, perforadas de manantiales para que los pozos pudieran dar agua. Los once secuaces de Tiamat fueron convertidos en estatuas y colocados en la puerta del Apsû para que nunca se olvidase lo que había acontecido... Marduk es entronizado y se le traspasa la soberanía 22

Una vez más, y en esta ocasión muy claramente, vemos el destino de la serpiente vencida y simbólicamente muerta, pero cuyo cuerpo es germen de nueva vida, en la que ella continúa en cierto modo una inmarcesible existencia: el propio mundo ordenado se configura a partir de sus restos. El combate es el paso previo a la cosmogonía.

\section{EL MITO EGIPCIO: LA SERPIENTE APOFIS}

En el curso de la líneas precedentes, el lector quizá ya haya dirigido su pensamiento hacia Egipto para recordar a la serpiente "todos los días vencida", la serpiente Apofis, una de las fuerzas más oscuras que amenazaban constantemente la $m a^{\prime} a t$, el principio que regía la existencia en su más amplia concepción, la base del mundo ordenado y al que se contraponía el ifset, equivalente a falsedad, injusticia, aunque con un sentido más amplio ${ }^{23}$. Sin duda, éste es uno de

\footnotetext{
${ }^{21}$ Unas líneas después de la expresión "pisó sus piernas" se nombra la cola debido al aspecto anguipedo con el que era imaginada la diosa. Quizá sean dos versiones que se han fundido en el poema, siendo posiblemente más reciente la que hace alusión a las piernas y más antigua la que se refiere a la cola.

22 J. BOTTÉRO, La religión más antigua: Mesopotamia, Madrid, 2001; F. LARA PEINAdO, Himnos sumerios, Madrid, 1988.

${ }^{23}$ N. COHN, El cosmos, el caos y el mundo venidero. Las letras de Drakontos, Barcelona, 1995.
}

los combates míticos más conocidos y paradigmáticos entre el dios del cielo y la serpiente.

Apofis, encarnación del caos primordial, había existido desde el principio de los tiempos: criada en las aguas primordiales anteriores a la creación, existía al margen del tiempo y del espacio, no tenía órganos sensitivos, no veía ni oía y solamente podía gritar ${ }^{24}$. Apofis se enfrentaba todas las noches a Ra, en la oscuridad, cuando la barca del sol realizaba su viaje nocturno a través del mundo inferior para emerger por el oriente. Era entonces cuando intentaba absorber el río imaginario por el que bogaba la barca y hacerla encallar con sus grandes anillos. Era Seth quien con su lanza, de pie en la proa de la barca, detenía el ataque de la serpiente a fin de que las aguas pudieran $\operatorname{brotar}^{25}$ (Lám. 4). Apofis era descuartizado, ensartado y quemado y su grito rompía las tinieblas. La ma'at vencía, pero nada estaba garantizado; a la noche siguiente el vencedor podía ser el ifset. La serpiente nunca podría ser definitivamente destruida. Apofis es el paradigma de serpiente nunca exterminada, ella siempre sobrevive, no puede ser aniquilada porque es inmortal, es el caos y éste existe siempre, es eterno. Mientras el mundo y los dioses tienen un inicio, el caos y sus monstruos no tienen principio ni fin. De él surge la vida y a él retorna; el propio Atón, al final de los días y a fin de subsistir en el magma líquido, comunica a Osiris que se convertirá en una serpiente que nadie conoce $e^{26}$.

El análisis de estos ejemplos de combates con la serpiente nos demuestran que el monstruo no es vencido totalmente en la contienda, o, por lo menos, no es "desterrado" y borrado de la faz de la tierra para no existir nunca más, sino que es adoptado en el nuevo mundo, como si se pretendiera que la dicotomía

\footnotetext{
${ }^{24}$ Este aspecto recuerda vivamente al monstruo hurrita de diorita, Ullikumi, monstruo ciego y sordo.

${ }^{25}$ Según E. CASANOVA y M. A. LARUMBE, La serpiente vencida. Sobre los origenes de la misoginia en lo sobrenatural, Zaragoza, 2005, p. 107, el enfrentamiento entre Seth y Horus no se manifestó hasta fines de la quinta dinastía (2245 a.C.). Antes de esto, Horus y Seth fueron adorados conjuntamente, lo que explicaría que fuese Seth, como alter ego de Horus, quien se enfrentara a la serpiente Apofis. Al mismo tiempo, esta teoría demostraría una Antigüedad casi inmemorial de este relato pues, aunque Norman Cohn sitúa la irrupción de este episodio en los textos del Primer Período Intermedio, parece claro que en esa época Seth ya era considerado un dios adversario, por lo que la creación del relato tuvo que tener lugar en la primeras dinastías.

${ }^{26}$ Libro de los muertos 175.
} 
entre las fuerzas de la luz y las de la oscuridad no terminara nunca o, quizá, porque esos elementos oscuros eran portadores de ciertos secretos que no debían ser olvidados y en este tipo de mitos de victoria del cielo frente a la tierra se deslizasen sin querer estas ideas que nos hablan de la presencia de la sabiduría antigua, ctónica en el nuevo mundo de los dioses uranios. No hay que olvidar que, en cierto modo, las serpientes del caos que retienen las aguas (aspecto común a muchos de estos monstruos: Tiamat, Vritra, Hedammu, Apofis, Tifón) cumplen el papel de serpientes guardianas custodias de un tesoro, en este caso un tesoro inmaterial simbolizado por las aguas: el Conocimiento. Es necesario derrotar a esos monstruos y hender su cuerpo para permitir que las aguas fluyan y el mundo pueda ser creado. Así, el conocimiento ancestral e intuitivo permanece en el nuevo mundo creado por el que se ha expandido ${ }^{27}$.

\section{LA MUERTE DE LA SERPIENTE PITÓN DE DELFOS}

En el mismo marco ideológico que acabamos de analizar se encuadra otro episodio mítico de hondas repercusiones culturales: la muerte de la serpiente Pitón en Delfos, aquel lugar privilegiado que fue considerado un

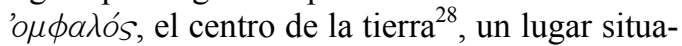
do en el monte Parnaso en el que se pensaba que era más fácil el contacto con la divinidad y en el que se conjugan los elementos más llamativos de la geografía griega: el agua, la montaña y la cueva. Fue en este centro de la tierra donde tuvo lugar el agón entre Apolo, el dios "recién llegado", y la serpiente Pitón, imagen de lo antiguo, de la tierra y custodia de la sabiduría ancestral ${ }^{29}$.

Este enclave era realmente especial, pues en él había una boca oracular que todos los indicios animan a identificar como un oráculo de Gea, a pesar de algunas notables voces discrepantes ${ }^{30}$. Gea, como reconoce Detienne, cuenta con una tradición cosmogónica que habla

${ }^{27}$ Cf. A. BARING y J. CASHFORD, El mito de la Diosa, Madrid, 2005. Véase también: C. G. JUNG, El hombre y sus símbolos, Barcelona, 1995, p. 118, sobre el ego y la sombra.

${ }^{28}$ Cf. VARRón, De lingua latina VII, 17. Introducción traducción y notas de M-A, MARCOS CASQUERO, Barcelona, 1990.

${ }^{29}$ J. Fontenrose, Python. A Study in Delphic Myth and its Origins, California, 1980

${ }^{30}$ M. DETIENNE, Apolo con el cuchillo en la mano, Madrid, 2001, p. 184 de sus virtualidades mánticas y en la que se hace patente su capacidad de conocer lo que va a suceder $^{31}$. En Delfos, la tierra sería el antecedente, la base sobre la que se fundamentan los poderes oraculares y adivinatorios, pues no parece posible negar a la tierra la posesión del saber ancestral que, en muchas ocasiones, comporta dotes mánticas, pues el conocimiento del pasado permite, a menudo, adivinar el posible futuro. Son muchos los relatos en los que las serpientes, íntimamente relacionadas con la tierra, dotan de poderes proféticos a seres humanos (Tiresias, Melampo...). A tenor de las fuentes antiguas se puede afirmar que en Delfos existió desde tiempo inmemorial un oráculo de la Tierra. Para Plutarco, éste era el oráculo más famoso y antiguo de Grecia. Diodoro Sículo nos transmite con todo lujo de detalles su descubrimiento y el motivo por el que se inventó el trípode para que en él se sentara la profetisa y fuese ella quien transmitiera los oráculos poseída por el éxtasis; pues en épocas precedentes, habiéndose descubierto de modo fortuíto las peculiaridades oraculares que emanaban de una hendidura de la tierra abierta en aquel lugar, la gente se acercaba a la grieta para efectuar consultas y, a menudo, en el curso del trance que experimentaban, se precipitaban por la grieta $\mathrm{y}$ morían $^{32}$. Pausanias nos cuenta que en los tiempos más remotos ya se creía que el oráculo pertenecía a Gea, quien nombró a Dafnis, una ninfa del bosque, como profetisa, así como que, en un poema hoy perdido titulado Eumolpia, se dice que el oráculo era común a Posidón y a Gea, que ella era la autora de oráculos y que Pircón era servidor de Posidón en los oráculos $y$ profecias $^{33}$. El hecho de que Posidón y Gea compartieran el oráculo no debería extrañar, si se tiene en cuenta el carácter del propio dios: Posidón reinaba sobre las aguas, sobre el mar, elemento profético por excelencia, y que además estaba ligado a la tierra. Los antiguos creían que los terremotos eran provocados por este dios, porque se pensaba que debajo de la tierra que pisaban había agua y el movimiento de éstas era lo que producía los seísmos. Además, Posidón era un antiguo dios de la tierra, delatado por toda una descendencia de hijos mons-

-

${ }^{31}$ M. DETIENNE, Apolo con el cuchillo en la mano, Madrid, 2001, p. 185.

32 PlutarCo, De defectu oraculorum 8 (=Moralia 414 A); Diodoro SícUlo, XVI, 26

${ }^{33}$ PAUSANIAS, X, 5, 6. Esta información la proporciona Museo. 
truosos que, en palabras de Gómez Espelosín, revelan su carácter de antiguo espíritu masculino de la fertilidad ${ }^{34}$, aunque posteriormente fue reducido al ámbito marino. Además, Posidón es el único olímpico que antecede a Apolo en el oráculo: tío de Febo, está muy relacionado con el dios pítico, con el que comparte grandes fundaciones en su papel de "Señor que posee la tierra" 35 . Por ello Detienne puede decir que Posidón parece predispuesto a desempeñar el papel de dios de los cimientos, el que ya está allí cuando se inaugura el proyecto de construir y fundar ${ }^{36}$.

Posidón acompaña a su sobrino ayudándolo de la forma más eficaz: estando ya allí cuando Apolo, divinidad joven, llega a aquel lugar a fundar el santuario ${ }^{37}$.

De las divinidades que ocuparon el sitio profético después de Gea y antes de Apolo no nos vamos a ocupar en este lugar en el que lo que nos interesa es resaltar la presencia de la Tierra en Delfos ${ }^{38}$, algo que, por otra parte, ya ha sido suficientemente discutido a lo largo de los años, así como el tipo de mántica que podría haberse dado en el santuario ${ }^{39}$.

Una vez establecida, a grandes rasgos, la presencia de Gea en vinculación con el oráculo délfico es el momento de dirigir nuestra atención al animal con ella relacionado: la serpiente

34 F. J. GÓMEZ ESPELOSÍN, Introducción a la Grecia Antigua, Madrid, 1998, p.89.

${ }^{35}$ M. DETIENNE, Apolo con el cuchillo en la mano, Madrid, 2001, p. 25.

${ }^{36}$ M. DETIENNE, Apolo con el cuchillo en la mano, Madrid, 2001, p. 25

${ }^{37}$ E. SuAREZ DE LA TORRE, "Le dieux de Delphes et l'histoire du sanctuaire (des origines au Ive siècle av. J.C.)", París, 1965.

${ }^{38}$ La presencia de Gea y de Temis en Delfos también está atestiguada físicamente, pues parece que Gea tuvo un pequeño santuario en el interior del témenos de Apolo, atestiguado por las cuentas de construcción del templo de Apolo en el s. IV a.C. E. SuÁrEZ DE LA TORRE, "Le dieux de Delphes et 1'histoire du sanctuaire (des origines au IVe sičcle av. J.-C.)", Kernos, 8, 1998, pp. 61-89. Otros elementos que corroborarían la antigua posesión del oráculo por Gea y Temis son los elementos naturalistas del mismo: el agua de la fuente Castalia y la supuesta falla del terreno por la que salía el hálito inspirador (hoy en día se sabe que no existía ninguna fisura al fondo del templo). El agua es un símbolo de lo antiguo y de lo preformal, así como de la sabiduría contenida en ello.

${ }^{39}$ Cf. P. AMANDRY, La mantique apollinienne à Delphes. Essai sur le fonctionnement de l'Oracle, París, 1950.
Pitón $^{40}$. Pero ¿quién era Pitón? La respuesta más frecuente en las fuentes clásicas a esta pregunta se resumiría de esta manera: Pitón era una serpiente (divina ${ }^{41}$ ) engendrada y enviada por la tierra para custodiar el lugar profético de Delfos. En ocasiones, parece que su función de guardiana aparece disimulada bajo el tópico del animal devastador, cual Hidra de Lerna ${ }^{42}$; no obstante, la aparición del agua, así como, más tarde, del árbol, proporciona las pistas que permiten identificarla como custodia del oráculo, versión más extendida en las fuentes antiguas. El testimonio de Eurípides es claro:

En este lugar, la serpiente de matizado dorso, de color vinoso, broncínea bajo la sombra del apretado laurel y prodigio monstruoso de la tierra, protege el oráculo ctonio [...] ocupando un palacio que es centro de la tierra ${ }^{43}$.

Como vemos, tenemos aquí un centro profético que además era el centro de la tierra, un ónfalos que, conectado con el árbol, se convierte en un axis mundi, el lugar donde se establece el contacto entre las tres zonas cósmicas, otorgándole de ese modo un carácter eminentemente sagrado ${ }^{44}$. Estos elementos se dejan ver especialmente bien en algunas monedas de época romana en los que la serpiente se enrolla en el árbol siguiendo esquemas que nos remiten a las representaciones de Ladón, el guardián del jardín de las Hespérides (Lám. 5). Estos aspectos naturalistas del oráculo vienen una vez más a corroborar la titularidad del mismo; el agua y el árbol, al igual que la serpiente, seguirán presentes en el santuario delfico tras el advenimiento de Apolo y no desaparecerán más que cuando los escritores cristianos rubriquen el fin de los días del santuario y se jacten de ello al decir:

El roble ya no deja oír su voz, el caldero ya no transmite oráculos... E inclu-

\footnotetext{
${ }^{40}$ Sobre las divergencias en cuanto al nombre de la serpiente en las fuentes y su significado no nos vamos a ocupar en este momento.

${ }^{41}$ Higino, Fábulas Prefacio.

${ }^{42}$ R. LÓPEZ MELERO, "La serpiente guardiana en la Antigua Grecia. Mito y Realidad", Héroes, semidioses y daimones. Ier Coloquio de Arys. Jarandilla de la Vera, Madrid, 2003, pp. 11-28.

${ }^{43}$ EURÍPIDES, Ifigenia en Táuride 1245-1257.

${ }^{44}$ H. B. RIESCO ÁlVAREZ, Elementos líticos y arbóreos en la religión romana, León, 1993, p.66.
} 
so Castalia ha callado y guarda silencio, y su ama ya no da profecías, sino risa ${ }^{45}$.

\section{$\mathrm{O}:$}

Han quedado reducidas al silencio las fuentes de Castalia y de Colofón, como han muerto todas las demás formas de adivinación por el fluir de las aguas, ya son inútiles los oráculos: el de Clarion, el Pition, el Didymeion ${ }^{46}$.

Junto a las referencias que sitúan a la serpiente como custodia del oráculo, algunas otras la convierten en la verdadera propietaria del mismo, siendo precisamente ella la que da las respuestas. Una de estas noticias, muy tardía, nos la ofrece el cristiano Paulo Orosio quien considera a Pitón creadora y fundadora de todo tipo de vaticinios ${ }^{47}$. Este testimonio nos muestra que todavía en el siglo $\mathrm{V}$ d. C. no resultaba extraño para un cristiano pensar en una serpiente como fundadora de un oráculo y reveladora de un misterios, aunque, para su mente cristiana, éstos fueran falsos.

Por lo tanto, tenemos una serpiente custodia de un enclave oracular e íntimamente ligada a la Tierra, por cuanto que, o bien es hija de Gea o quizá una epifanía de la propia diosa y, en todo caso, una serpiente sagrada. Contra este rival es con quien se enfrenta el precoz Apolo a su llegada a Pitón ${ }^{48}$. Tal es el tema de un grupo de lecitos áticos de figuras negras del segundo cuarto del siglo $\mathrm{V}$ a. $\mathrm{C}^{49}$ : Apolo niño, en brazos de su madre dispara a la serpiente que sale de una cueva ${ }^{50}$ (Lám. 6). De igual modo es de

45 Gregorio NaCianceno, Contra el emperador Juliano II, 32. Se refiere al roble sagrado y los calderos de bronce existentes en el oráculo de Zeus en Dodona. En este santuario, las profecías se realizaban, entre otros elementos, en base al rumor de las hojas del roble sagrado y al resonar de los calderos de bronce. También ligados a este oráculo se encontraba una fuente sagrada, las voces de las palomas del árbol sagrado y los dichos de las Peleíades, las sacerdotisas.

46 Clemente de Alejandría, Proptréptica II, 11, 1. El santuario de Apolo Clarios se situaba en territorio de Colofón, en la costa jonia $\mathrm{y}$, aunque también contaba con una gran antigüedad, no tuvo hasta época helenística fama panhelénica. El oráculo de Apolo en Dídima, Dydimeion, era, así mismo, muy antiguo, e incluso remontaba su existencia a una época anterior a la llegada de los jonios.

${ }^{47}$ Paulo Orosio, Historias VI, 14, 15.

48 Antiguo nombre de la ciudad de Delfos.

${ }^{49}$ T. CARPENTER, Arte y mito en la antigua Grecia, Barcelona, 2001, p. 72.

${ }^{50} \mathrm{La}$ serpiente de la montaña se halla relacionada, en realidad, no con las alturas, sino con las grutas, ya que se destacar la dimensión totalmente humana a la que Praxíteles redujo la representación de este episodio mitológico: aquí un dios pusilánime y con cierto desinterés se dispone a matar, no a una temible serpiente, sino a un inofensivo lagarto que trepa por un árbol (Lám. 7).

Una vez que la serpiente perece asaeteada por las flechas disparadas por Apolo, éste se convierte en el nuevo rey del oráculo délfico. No obstante, un hecho de suma importancia tiene lugar antes de que esto acontezca: Apolo ha de purificarse por la muerte del ofidio y es este ritual el que nos da la clave para entender la magnitud del acto que acaba de cometer: un sacrilegio. Esa necesidad de ser purificado pone de relieve que la serpiente a la que ha matado no era un animal cualquiera, un monstruo peligroso cuyo exterminio pudiera ser elogiado por los hombres, sino una criatura dotada de tan especiales características religiosas que exigen que incluso un dios se purifique del miasma que supone el derramamiento de su sangre. ¿Por qué si no encaminarse hacia los confines de la Hélade, a Creta, en busca de Carmanor, para purificarse huyendo de espiritus justicieros y de los vengadores de la sangre derramada ${ }^{51}$ ? Un fragmento citado por Detienne (PAUSANIAS, II, $7,7)$ presenta en primer plano la muerte de la serpiente interpretada como un asesinato: Ártemis y Apolo tienen una visión de terror o un signo espantoso que surge en caso de polución importante y de las profundidades de la noche $e^{52}$, visión común a la de otros asesinos de la mitología clásica.

Una Serpiente Sagrada ha sido asesinada, la tierra ha sido vencida y subyugada y se ha impuesto el peán; no obstante, como ya hemos visto en páginas precedentes, no resulta tan fácil deshacerse de las potencias ctónicas y, en este caso, no iba a ser menos. Una vez más, la serpiente seguirá presente en el nuevo orden que ahora se instaura: sus huesos fueron depositados en el trípode y su piel se aprovechó para recubrirlo; se creyó también que la piedra que marcaba el ónfalos -axis mundi por antonomasiaera un monumento a la serpiente, situado justo

creía que, al igual que las cuencas fluviales, las grutas eran entradas al otro reino. Cf. V. PROPP, Las raices históricas del cuento, Madrid, 1974.

${ }^{51}$ Plutarco, De defectu Oraculorum 15 (=Moralia 414 B).

${ }^{52}$ M. Detienne, Apolo con el cuchillo en la mano, Madrid, 2001, p. 223. 
en el centro del mundo... Por si esto fuera poco, se instauraron unos juegos en su memoria y, anualmente, unas fiestas (septerion) rememoraban lo que había acontecido. Un relieve de Mileto (Lám. 8) resulta un revelador compendio de

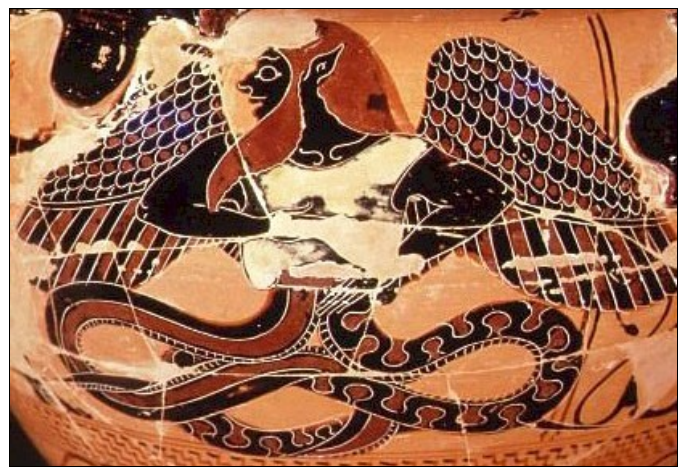

- Lám. 1. Hidria Calcidia del S.VI a.C con representación de Tifón (Antikensammlungen Museum 596).

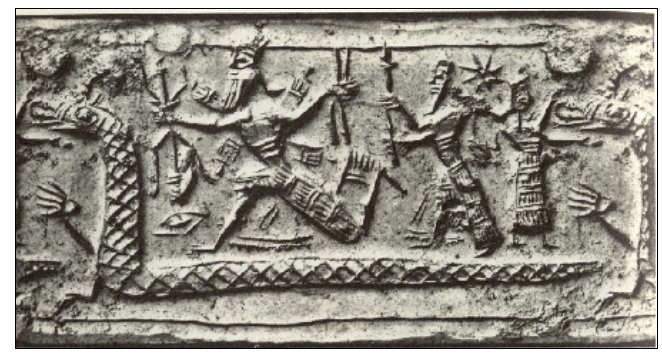

- Lám. 3. Estampa de cilindro-sello babilonio ca.S.IX-VIII a.C. representando el combate de Marduk contra Tiamat (Londres, British Museum). cuanto hasta aquí hemos expuesto: Apolo ya se ha convertido en el rey del oráculo, aparece sentado sobre el ónfalos, con el arco, el trípode y el árbol; pero en la parte inferior de la escena, agazapada, sigue viva la serpiente... ${ }^{53}$

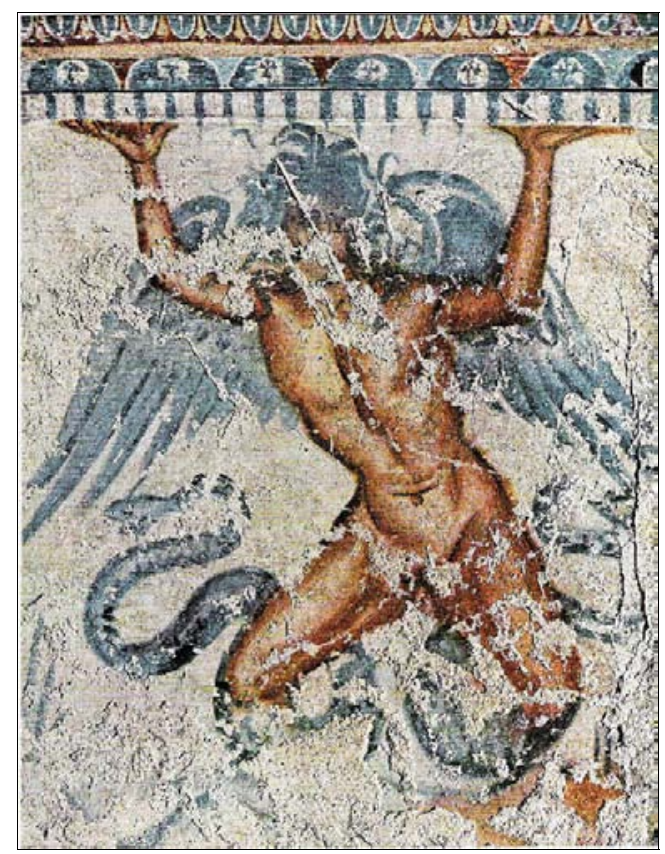

- Lám. 2. Pintura mural con figura de Tifón (Tumba de Tifón, Tarquinia).

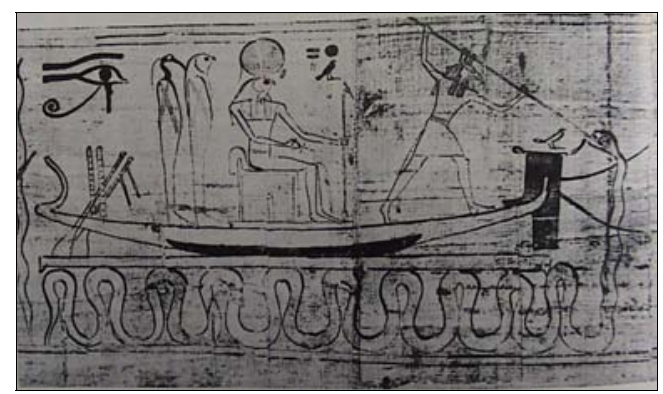

- Lám. 4. Seth alancea a la serpiente Apofis en el viaje nocturno de la barca solar. Libro de los Muertos de la señora Heriwebeshet. 1085-950 a.C. (El Cairo, Museo de El Cairo).

${ }^{53}$ LIMC, Zürich, 18 vol., 1981-1999. (Apollo). Véase también F. BROMMER, Göttersagen in Vasenlisten, Marburg, 1980. E. GRABOW, Schlangenbilder in der griechischen schwarzfigurigen Vasenkunst, Paderborn, 1998. 


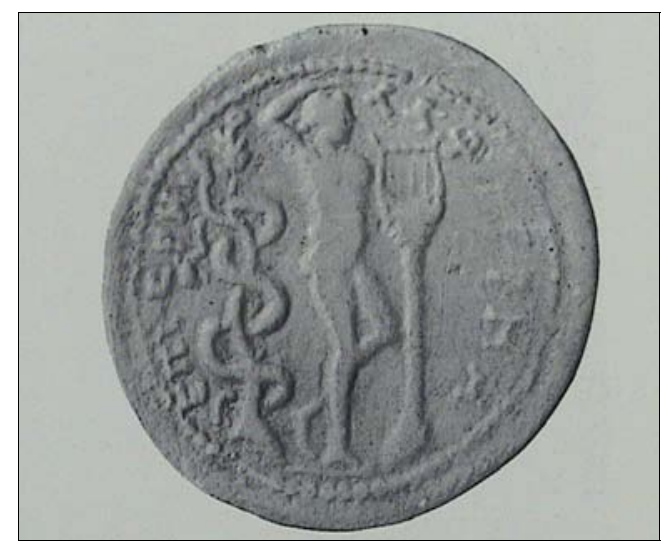

- Lám. 5. Moneda de plata de Cómodo en la que aparece figurado Apolo con la lira, el árbol y la serpiente. 215 d.C.

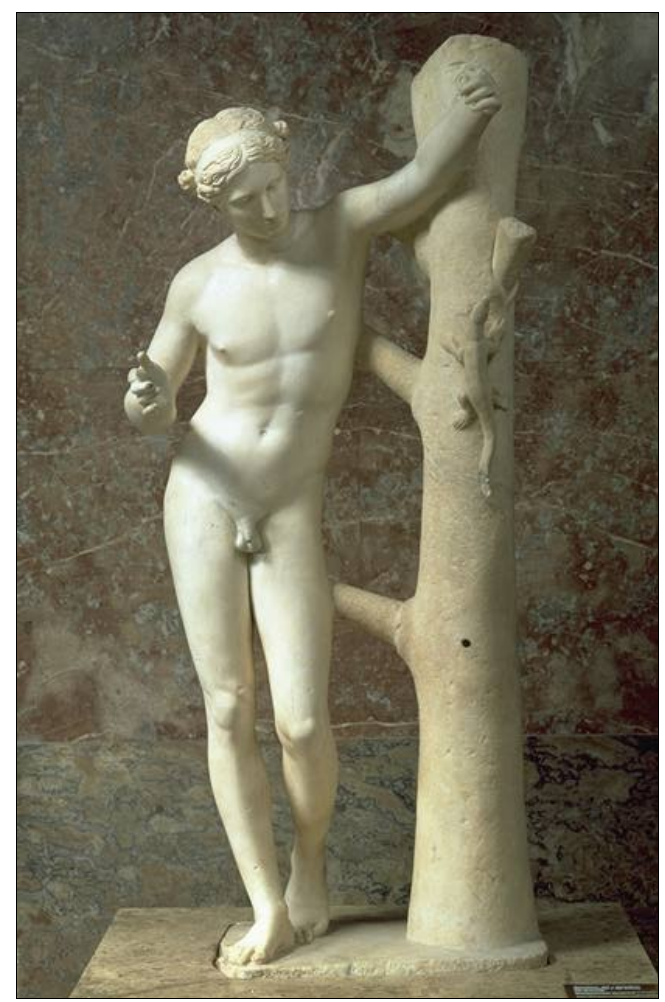

- Lám. 7. Copia romana del Apolo Sauróctono de Praxiteles (París, Museo del Louvre).

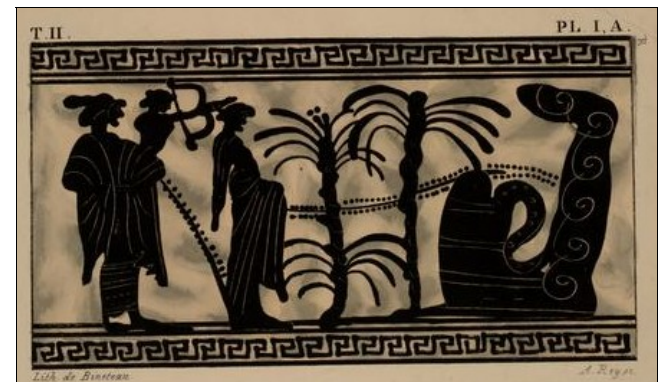

- Lám. 6. Litografía presentada por John Ruskin al Ruskin Drawing School (University of Oxford) en 1875 y transferida al Ashmolean Museum en 1949. Lecito ateniense de figuras negras (París, Cabinet des Medailles, 306).

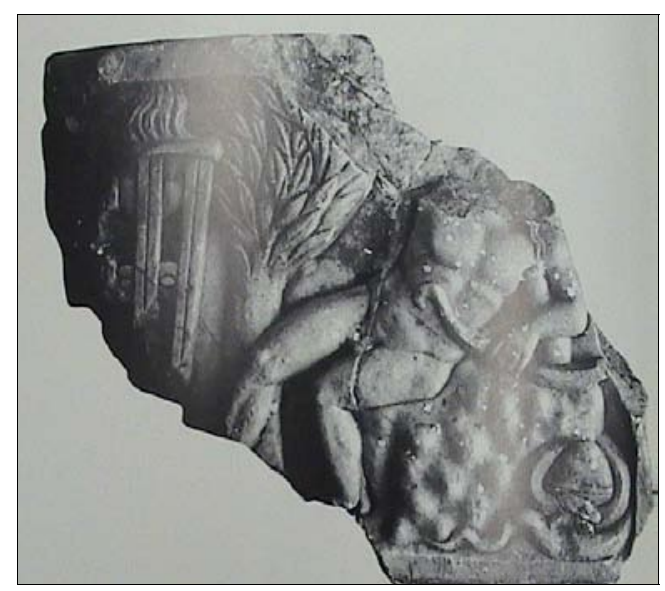

- Lám. 8. Relieve representando a Apolo sobre el ónfalos procedente de Mileto S. IV d.C. (Délos, Museo de Delos 186). 